\title{
LAS TRAMPAS AL SOLITARIO O LA REFORMA ELECTORAL ARAGONESA DE 2019
}

\author{
Enrique Cebrián Zazurca \\ Profesor de Derecho Constitucional, \\ Universidad de Zaragoza
}

Cómo citar este artículo / Citation: Cebrián Zazurca, E. (2021).

Las trampas al solitario o la reforma electoral aragonesa de 2019.

Palacios Romeo, F. y Cebrián Zazurca, E. (coords.)

Elección y representación: una conjunción compleja. Perspectivas y problemas de los regímenes electorales en España, Colección Obras colectivas, Fundación Manuel Giménez Abad, Zaragoza.

DOI: https://doi.org/10.47919/FMGA.OC21.0308

En memoria de Joaquín Carbonell

El camino que en los primeros años ochenta del pasado siglo condujo a la aprobación del Estatuto (EAAr) y a la formación de la Comunidad Autónoma de Aragón fue tortuoso y accidentado ${ }^{1}$. Presidido por la disputa en torno a la vía más adecuada para el acceso a la autonomía, la confrontación entre los partidarios del artículo 143 de la Constitución (CE) y aquellos que apostaban por el $151 \mathrm{CE}$, lejos de representar un debate estrictamente procedimental, apenas ocultaba los planes e intencionalidades políticas subyacentes ${ }^{2}$.

\footnotetext{
Una descripción detallada del proceso autonómico aragonés puede seguirse en CONTRERAS CASADO, M., El Estatuto de Autonomía de Aragón. Las bases jurídico-políticas y documentales del proceso autonómico aragonés, vol. I, Cortes de Aragón, Zaragoza, 1987; CONTRERAS CASADO, M., "Aragón", en ESPÍN TEMPLADO, E. (Coord.), La Constitución de 1978 y las Comunidades Autónomas, Centro de Estudios Políticos y Constitucionales, Madrid, 2003, pp. 51-76 y en GARRIDO LÓPEZ, C., Demanda regional y proceso autonómico. La formación de la Comunidad Autónoma de Aragón, Tecnos - Gobierno de Aragón, Madrid, 1999. ${ }^{2}$ Traté de presentar un panorama de esa tensión en CEBRIÁN ZAZURCA, E., "Derecho y política en la construcción del Estado autonómico. Algunas reflexiones a propósito del Dictamen de la Cátedra de Derecho Político de la Universidad de Zaragoza de 12 de febrero de 1980", en MARTOS CONTRERAS, E., QUIROSA-CHEYROUZE, R. y SABIO ALCUTÉN, A. (eds.), 40 años de Ayuntamientos y Autonomías en España, Asociación de Historiadores del
} 
Mezclada entre todo ello, y como elemento principal, surgió la discusión en torno a la magnitud de las circunscripciones en las futuras elecciones al Parlamento autonómico. De esta manera, desde los ayuntamientos de Teruel en manos de la Unión de Centro Democrático (el ochenta por ciento de los de la provincia), se sometió la adopción de los necesarios acuerdos de iniciativa autonómica a la exigencia, que habría de ser contemplada en el Estatuto, en virtud de la cual a las tres provincias aragonesas les correspondería en las Cortes de Aragón igual número de representantes, independientemente de la población de cada una de ellas.

Se pretendía de esta manera confeccionar desde las instituciones un contrapeso al "presunto izquierdismo de Zaragoza capital", tratando de "podar la proporcionalidad en aras de una sedicente representación territorial que en puridad buscaba primar el voto rural, ideológicamente muy distinto al urbano"3. El proceso autonómico se vio abocado a un aparente callejón sin salida, y el desbloqueo tuvo que llegar, entre otras medidas, con la decisión de transitar la vía del artículo $143 \mathrm{CE}$, acompañada del abandono de la pretensión de la igualdad territorial en el que habría de ser el Parlamento aragonés.

Así, cuando en agosto de 1982 se aprueba el EAAr encontramos el artículo 18.3, que afirmaba, en cumplimiento de lo dispuesto en el artículo 152.1 CE: "La elección [de los diputados de las Cortes de Aragón] se verificará atendiendo a criterios de representación proporcional, que asegure, además, la representación de las diversas zonas del territorio". El artículo 19 EAAr establecía: "Las Cortes de Aragón estarán integradas por un número de Diputados comprendido entre sesenta y setenta y cinco, correspondiendo a cada circunscripción electoral un número tal que la cifra de habitantes necesarios para asignar un Diputado a la circunscripción más poblada no supere dos, setenta y cinco veces la correspondiente a la menos poblada".

Tras la reforma del EAAr de 2007, los contenidos del antiguo 18.3 y 19 pasaron a formar parte respectivamente de los artículos 37.3 y 36 , si bien continuaron presentando sustancialmente el mismo tenor, con la salvedad de que la

Presente - Servicio de Publicaciones de la Universidad de Zaragoza, Zaragoza, 2019, pp. 6886.

${ }^{3}$ CHUECA RODRíGUEZ, R. L., "Régimen electoral de la Comunidad Autónoma de Aragón", en EMBID IRUJO, A. (Dir.), Derecho Público Aragonés. Estudios sobre el Derecho de la Comunidad Autónoma de Aragón, El Justicia de Aragón - Ibercaja, Zaragoza, 1990, pp. 51-85 (p. 75). 
horquilla que comprende el número posible de representantes en las Cortes de Aragón ascendió, situándose ahora entre sesenta y cinco y ochenta.

Fue la Ley 2/1987, de 16 de febrero, Electoral de la Comunidad Autónoma de Aragón (LEAr) la que se aprobó para regular las elecciones al Parlamento aragonés. Su artículo 13 establecía lo siguiente:

1. Las Cortes de Aragón están formadas por sesenta y siete diputados.

2. A cada provincia le corresponde un mínimo inicial de trece diputados.

3. Los veintiocho diputados restantes se distribuyen entre las provincias, en proporción a su población, conforme al siguiente procedimiento:

a) Se obtiene una cuota de reparto resultante de dividir por veintiocho la cifra total de la población de derecho de las tres provincias.

b) Se adjudican a cada provincia tantos diputados como resulten, en números enteros, de dividir la población de derecho provincial por la cuota de reparto.

c) Los diputados restantes se distribuyen asignando uno a cada una de las provincias cuyo coeficiente, obtenido conforme al apartado anterior, tenga una fracción decimal superior.

4. El decreto de convocatoria deberá especificar el número de diputados a elegir en cada circunscripción, de acuerdo con lo dispuesto en este artículo.

Lo recogido en la norma electoral aragonesa omitía la parte del entonces artículo 19 EAAr relativa al límite por el cual el número de habitantes requerido para asignar un diputado a la provincia más poblada no podía superar en 2,75 veces al número de habitantes requerido para asignar un diputado a la provincia menos poblada. Siendo esto así, fue doce años después, cuando por medio de la Ley 10/1999, de 14 de abril, se modificó la LEAr. Como se explicaba en el Preámbulo de la norma, la evolución poblacional de Aragón podía dar lugar a que, aplicando únicamente las reglas contenidas en el artículo 13 LEAr, se superase la barrera establecida en el EAAr. Por tal motivo, "se hace preciso colmar la laguna existente en la Ley electoral mediante la oportuna cláusula de cierre que prevea las consecuencias de la norma fijada por nuestro Estatuto de Autonomía. Se trata, pues, de llenar el vacío existente mediante una norma que, sin alterar el mecanismo diseñado por la Ley electoral y en aras de la seguridad jurídica, contemple las consecuencias del 
límite establecido por el artículo 19 del Estatuto". La reforma añadió un nuevo apartado cuarto al artículo 13 LEAr (el contenido del hasta entonces apartado cuarto pasó así a formar parte de un quinto apartado), en los siguientes términos:

Si, como consecuencia de la aplicación de las reglas anteriores, el número de habitantes dividido por el número de escaños en la provincia más poblada superara en 2,75 veces al de la provincia menos poblada, corresponderá a la provincia de mayor población el número de Diputados de la provincia de menor población que sea indispensable para que no se supere dicho límite.

Esta fue hasta el año 2019 la redacción del artículo 13.4 LEAr. ¿Qué sucedió en ese momento para que se llevase a cabo la reforma de la que vamos a ocuparnos en estas páginas? Lo que ocurrió fue que 2019 era año electoral y el 26 de mayo iban a celebrarse elecciones a las Cortes de Aragón. A comienzos del año se advirtió que, atendidos los datos de población, la provincia de Teruel iba a perder un escaño que pasaría a corresponderle a la de Zaragoza. De ese modo el reparto de escaños existente -35 para Zaragoza, 18 para Huesca y 14 para Teruel- se vería modificado, quedando Huesca igual y correspondiendo 13 diputados a Teruel y 36 a Zaragoza. No se trataba de una cuestión de la que no se hubiera podido tener conocimiento antes, y en su caso haber arbitrado las medidas que se estimasen oportunas, puesto que como bien ha recordado la profesora y Letrada de las Cortes aragonesas, Olga Herráiz, "(e)n las elecciones autonómicas de 2015, los datos del padrón de Teruel habían salvado el escaño 14 por apenas 300 habitantes"4. Postergado el asunto desde el inicio de la legislatura, no fue hasta casi su final cuando se reparó en él, tratando de hallar una rápida solución. Al fondo latía el temor ante la consecuencia de una situación que, si bien podía verse como menor, poseía una fuerte carga simbólica. El que Teruel tenga un diputado más o menos no se traduce directamente en consecuencias positivas o negativas para la provincia, "toda vez que la representación que se actúa es política, o sea, articulada a través del grupo parlamentario correspondiente" ${ }^{\text {; }}$ es decir, las bondades o perjuicios lo serán para partidos políticos concretos. Pero, si bien

\footnotetext{
${ }^{4}$ HERRÁlZ SERRANO, O., "Crónica parlamentaria de la IX Legislatura (2015-2019) en las Cortes de Aragón", Revista Aragonesa de Administración Pública, núm. 54, 2019, pp. 399-450 (p. 435).

${ }^{5}$ CHUECA RODRÍGUEZ, R. L., "Régimen electoral de la Comunidad Autónoma de Aragón", en EMBID IRUJO, A. (Dir.), op. cit., p. 77.
} 
esto es cierto, también lo es que una presencia mayor puede facilitar la inclusión en el debate político de temas de interés para ese territorio. Con todo, la verdadera razón fue, como en otro lugar expuse, la siguiente: "Que la provincia aragonesa menos poblada -una de las provincias, además, que de manera más clara representa a escala nacional la problemática de la conocida como 'España vacía'- perdiera un asiento en las Cortes en beneficio de la provincia aragonesa más poblada fue visto por las distintas fuerzas políticas como algo cuya defensa de cara a la opinión pública -y más ante la inminencia de un proceso electoral- podría resultar impopular"6. La cuestión surgió en un momento en el que aparecía como uno de los temas sobresalientes del debate público un asunto -la despoblación- que en Aragón siempre había tenido un protagonismo esencial. El profesor Carlos Garrido ya dio a finales de los años noventa buena cuenta de cómo ese fenómeno fue determinante a la hora de conformar una conciencia y una visión de Aragón como espacio subdesarrollado, que terminaría jugando un papel principal en la demanda en favor del autogobierno ${ }^{7}$. Los pueblos abandonados, las casas vacías, la emigración han constituido tradicionalmente un grueso hilo temático que ha configurado de manera poderosa la simbología acerca del "ser" de un territorio, que encontró en las manifestaciones culturales y muy especialmente en la canción popular -en el movimiento que se conoció como nueva canción aragonesa $a^{8}$ una importante vía de expresión. No por casualidad, como ha recordado Alberto Sabio, “(e)n el caso de Aragón, en el origen de buena parte de los cantautores estuvo Teruel"9 . Esta temática, como digo, está viviendo de un tiempo a esta parte una (re)vitalización en toda España, en la que Aragón y, una vez más, en algunos casos especialmente Teruel- marca la pauta en buena medida. Plataformas ciudadanas como Teruel Existe, que con carácter

\footnotetext{
${ }^{6}$ CEBRIÁN ZAZURCA, E., "Crónica de las elecciones a las Cortes de Aragón de 26 de mayo de 2019", Cuadernos Manuel Giménez Abad, núm. 18, 2019, pp. 89-93 (p. 89).

7 "Las áreas industrializadas y urbanizadas requerían mano de obra, lo que provocaba la emigración masiva y selectiva en todas las demás. El resultado, la despoblación y el desequilibrio socioprofesional de la periferia. Paradójicamente, los recursos financieros y el ahorro de las regiones subdesarrolladas servían para impulsar la inversión y satisfacer las necesidades de capital de las zonas más industrializadas", en GARRIDO LÓPEZ, C., Demanda regional y proceso autonómico. La formación de la Comunidad Autónoma de Aragón, op. cit., p. 60 .

${ }^{8}$ El 13 de noviembre de 1973 se celebraron en el Teatro Principal de Zaragoza los dos conciertos que -bajo el título Primer Encuentro de la Música Popular en Aragón- sirvieron como carta de presentación de este movimiento musical. En 2019 la editorial Prames publicó un libro-disco con dos cedés con la grabación de aquel día.

9 SABIO ALCUTÉN, A., "Joaquín Carbonell y la emoción en la Transición", en el libro-disco Carbonell 50 años. 1969-2019, Voces del Mercado, La Joyosa (Zaragoza), 2020.
} 
posterior a los hechos comentados en estas páginas dio el salto a la política parlamentaria española con éxito muy notable, y que sirvió de guía para otros movimientos ciudadanos en otras provincias, es un claro ejemplo de ello. Pero esto también se ve de nuevo en el propio ámbito de la cultura: la publicación en 2016 del exitoso ensayo La España vacía de Sergio del Molino supuso el hito definitivo para poner el foco de la opinión pública en la despoblación e incluso para designar el problema ${ }^{10}$. Tras esta, otras obras han tratado la cuestión desde perspectivas y géneros literarios muy diversos, así Fernando Collantes y Vicente Pinilla, profesores de Historia Económica de la Universidad de Zaragoza, han publicado en 2019 el estudio ¿Lugares que no importan? La despoblación de la España rural desde 1900 hasta el presente ${ }^{11}$; el profesor, poeta y dinamizador cultural Víctor Guiu publicaba a finales de ese mismo año 2019 un ensayo a mitad de camino entre la sociología y el relato personal, en el que no falta la ironía, bajo el provocador título de Lo rural ha muerto, viva lo rural. Otro puñetero libro sobre la despoblación ${ }^{12}$ y, sin querer ser exhaustivo, en 2020 ha aparecido la novela titulada Un hípster en la España vacía, en la que el escritor Daniel Gascón plantea este y otros asuntos desde la óptica del humor ( $\mathrm{y}$ cuyos derechos ha adquirido Netflix para convertirla en una serie) ${ }^{13}$. Estamos hablando en todos estos casos, casualidad o no, de autores aragoneses.

Volviendo sobre lo acontecido en 2019, de lo que se trataba era de articular en unos pocos meses una rápida solución que evitase que en las elecciones autonómicas de mayo Teruel perdiese un escaño -que ganaría Zaragoza- en las Cortes de Aragón. Por encargo de la Junta de Portavoces de las Cortes de Aragón, los Servicios Jurídicos de la cámara, concretamente la Letrada Mayor Dña. Carmen Agüeras Angulo y el Letrado D. Adolfo Alonso Ortega, elaboraron un muy exhaustivo y detallado Informe en el que, con fecha de 18 de enero de 2019, presentaban y analizaban hasta quince opciones dirigidas a salvar el escaño número catorce de la provincia de Teruel. La primera opción, que habría solucionado el problema, consistía en subir la cifra que aparece en el

\footnotetext{
${ }^{10}$ MOLINO, S. del, La España vacía. Viaje por un país que nunca fue, Turner, Madrid, 2016.

${ }^{11}$ COLLANTES, F. y PINILLA, V., ¿Lugares que no importan? La despoblación de la España rural desde 1900 hasta el presente, Prensas de la Universidad de Zaragoza, Zaragoza, 2019 (se trata, en realidad, de la traducción al español de la obra que con el título Peaceful Surrender: The Depopulation of Rural Spain in the Twentieth Century publicaron estos mismos autores en Reino Unido en 2011).

${ }_{12}$ GUIU, V., Lo rural ha muerto, viva lo rural. Otro puñetero libro sobre la despoblación, Dobleuve Comunicación, Teruel, 2019.

${ }^{13}$ GASCÓN, D., Un hípster en la España vacía, Penguin Random House, Barcelona, 2020.
} 
artículo 36 EAAr de 2,75 a 2,85. Esta subida de 0,10 impediría que Teruel perdiera el diputado. Sin embargo, de entrada se descartó puesto que no era ya posible en ese momento muy final de la legislatura emprender un proceso de reforma estatutaria. Eliminada esta opción, existían dos posibles líneas de acción: a) reformar el mínimo fijo de escaños por circunscripción, o b) actuar dentro de la horquilla (sesenta y cinco-ochenta) de diputados permitida por el EAAr.

Dentro de la opción a) se analizaron diez posibilidades. Veamos su planteamiento y los efectos que hubieran producido:

a1) Disminuir de trece a diez el número fijo de escaños por circunscripción. Se rechazó porque el número de escaños de Huesca hubiera bajado a dieciséis.

a2) Disminuir de trece a once el número fijo de escaños por circunscripción. Se descartó porque el número de escaños de Huesca hubiera bajado a diecisiete.

a3) Disminuir de trece a doce el número fijo de escaños por circunscripción. Se descartó también porque Huesca igualmente hubiera bajado a diecisiete escaños.

a4) Subir de trece a catorce el número fijo de escaños por circunscripción. Se rechazó porque, tras realizar los cálculos correspondientes, el resultado final sería el mismo que aplicando las normas ya existentes, esto es, dieciocho escaños para Huesca, trece para Teruel y treinta y seis para Zaragoza.

a5) Subir de trece a quince el número fijo de escaños por circunscripción. Se eliminó porque, por un lado, Teruel quedaría tras los cálculos con menos diputados que los quince que se habían establecido y porque, por otro lado, Huesca quedaría sobrerrepresentada con diecinueve diputados.

a6) Dejar el número fijo de escaños de Zaragoza en trece y subir a catorce el de las dos provincias menos pobladas (Teruel y Huesca). Se excluyó porque, de nuevo, Teruel quedaba tras los cálculos con menos diputados que los fijados de inicio, que eran catorce. 
a7) Mantener el número fijo de trece escaños a la provincia menos poblada (Teruel) y bajarlo a doce a las dos más pobladas (Zaragoza y Huesca). Se rechazó porque Teruel finalmente quedaría solo con esos mismos trece escaños asignados de inicio, con lo que perdería igualmente el escaño número catorce y porque, además, Zaragoza quedaría sobrerrepresentada con respecto a Teruel (trece escaños) y a Huesca (diecisiete escaños), ya que estas dos provincias perderían un escaño en comparación con la situación actual.

a8) Asignar un número fijo de escaños de manera progresiva en función de la población, de modo que Teruel cuente con trece escaños, Huesca con catorce y Zaragoza con quince. Se eliminó porque, tras aplicar los cálculos, Teruel quedaría con menos diputados que los catorce con los que hoy cuenta.

a9) Asignar un número fijo de escaños de manera progresiva en función de la población pero otro distinto, de forma que Teruel cuente con catorce escaños, Huesca con quince y Zaragoza con dieciséis. Se descartó porque, otra vez, tras aplicar las reglas, Teruel quedaría por debajo de los catorce escaños que hoy tiene y porque Huesca ganaría un escaño más (diecinueve en total) con respecto a la situación actual.

a10) Asignar un número fijo de escaños de manera regresiva en función de la población, contando así Teruel con quince escaños, Huesca con catorce y Zaragoza con trece. Se rechazó porque una vez más Teruel quedaría finalmente por debajo de los catorce diputados con los que cuenta en la actualidad.

Descartadas todas estas opciones, se estudiaron otras cuatro dentro de la opción b), dirigidas a actuar en la horquilla de diputados establecida en el EAAr. Veamos cómo fueron planteadas y sus posibles efectos:

b1) Establecer un Parlamento de sesenta y seis escaños. Se excluyó porque, en primer lugar, aplicadas las reglas pertinentes, Teruel quedaría con trece diputados (igual que en la situación que se trataba de evitar) y, en segundo lugar, porque además se perjudicaría también a Huesca (que bajaría a diecisiete diputados), siendo Zaragoza la provincia beneficiada en ambos casos (pasaría a treinta y seis diputados). 
b2) Establecer un Parlamento de sesenta y cinco escaños. Se descartó porque, realizados los cálculos, tanto Teruel como Huesca perderían representación, mientras que Zaragoza permanecería igual. Concretamente Teruel quedaría con trece diputados (lo que se trataba de evitar) y Huesca con diecisiete.

b3) Establecer un Parlamento de sesenta y ocho escaños. Se rechazó porque finalmente Teruel contaría con trece diputados (de nuevo, lo que se trataba de evitar) y además Zaragoza subiría de 35 a 37 diputados (dos diputados más que ahora y uno más que si no se modificase nada).

b4) Establecer un Parlamento de sesenta y nueve escaños. El resultado de esta opción se traduciría en dieciocho diputados para Huesca, catorce para Teruel y treinta y siete para Zaragoza. Como se pone de manifiesto en el Informe, "(e)sta es la única opción que mantiene la representación actual de Teruel y Huesca. Supone incrementar en dos los escaños que conformarían las Cortes de Aragón, ambos en favor de la circunscripción de Zaragoza".

Como se ve, y una vez descartada la posibilidad de reformar el EAAr, que habría representado la opción más correcta, de las otras catorce alternativas ofrecidas en este Informe solo esta última cumplía con el objetivo de mantener los catorce escaños de la circunscripción turolense, si bien sumando dos diputados más a Zaragoza. Se cumplía, por tanto, de algún modo el objetivo, si bien quizás no tanto si se analiza desde una visión más general, por cuanto ese mantenimiento se lograba a costa de aumentar todavía más la diferencia en número de escaños entre la provincia menos poblada y la más poblada, añadiendo dos más a esta última. En todo caso, como ha señalado Olga Herráiz, este camino no se exploró debido al aumento del gasto público que conllevaba, algo difícil de defender en un "contexto de desafección ciudadana" como el actual ${ }^{14}$. Fue otra la senda que comenzó a transitarse por todos los Grupos y Agrupaciones de las Cortes aragonesas, a excepción del Grupo Popular, que el 14 de marzo registraron una Proposición de Ley dirigida a reformar la LEAr. La reforma consistiría en basarse en otra categoría hasta entonces no utilizada, como era la de población censal. De este modo, una vez descontados los trece diputados con los que directamente cuenta cada

\footnotetext{
${ }^{14}$ HERRÁIZ SERRANO, O., "Crónica parlamentaria de la IX Legislatura (2015-2019) en las Cortes de Aragón”, op. cit., p. 433.
} 
circunscripción, la asignación de los otros veintiocho que restan se haría tomando como referencia la población censal de cada provincia y no la población de derecho. Si la distribución de escaños se llevaba a cabo de esta manera quedaba demostrado que se mantenía el decimocuarto escaño de Teruel y que además los de Huesca y Zaragoza tampoco sufrían modificación, es decir, la composición de la cámara en cuanto al reparto provincial de asientos quedaba inalterada.

Para determinar la viabilidad de esta solución, un nuevo Informe jurídico fue solicitado. El Informe se emitió con fecha 18 de marzo y estaba firmado por la Letrada Mayor. El mismo incluía unas consideraciones previas de especial relevancia. Así, se afirmaba lo siguiente: "Los Letrados parlamentarios realizamos el asesoramiento a los parlamentarios en el ámbito legislativo con carácter general en el seno de los órganos parlamentarios (...) respetando los límites que en materia de calificación ha ido decantando la jurisprudencia constitucional, que impiden el estudio del fondo jurídico de las iniciativas parlamentarias, fuera de un somero análisis liminar; y nunca realizamos análisis jurídicos de constitucionalidad o legalidad previos o apriorísticos sobre las iniciativas legislativas que presenta el Gobierno (Proyectos de Ley) o los Grupos parlamentarios (Proposiciones de Ley). Desde este punto de vista la situación producida en este caso es anómala". A esta anomalía se iban a sumar otras dos, consistentes en la petición asimismo de sendos informes a los Servicios Jurídicos del Gobierno de Aragón y al Consejo Consultivo de Aragón, lo cual habría creado -en palabras de la Letrada Mayor- "un precedente no deseable, en cualquier caso, de consecuencias impredecibles". Como se señalaba en el Informe, no era en absoluto procedente que órganos gubernamentales "supervisasen" la iniciativa legislativa del Parlamento. Finalmente, estos otros dos informes no llegaron a ser solicitados.

El Informe emitido por la Letrada Mayor, que pese a todo entró en el fondo del cambio normativo que se proponía, valoraba si este podía "vulnerar alguno de los derechos constitucionales relacionados con la participación política o la representación, o alguno de los elementos de configuración constitucional que delimitan el margen de actuación normativo en esta materia" y terminó por considerar que la propuesta de modificación legislativa era ajustada a Derecho. Tres fueron con carácter principal los elementos en torno a los cuales se planteó el análisis: la representación, la igualdad y la proporcionalidad. Se 
concluyó que el cambio no afectaría a lo dispuesto en el artículo 33.1 EAAr ("Las Cortes de Aragón representan al pueblo aragonés..."), como tampoco al principio del voto "igual" (artículo 37.1 EAAr). Asimismo, se estimó que tampoco la proporcionalidad a la que obliga el artículo 152.1 CE se vería afectada, recordando para ello las posiciones que podrían calificarse de "matemática creativa" mantenidas por Gobierno y grupos parlamentarios y resumidas en afirmaciones como “... ni los grupos presentes en la Cámara aragonesa ni el Gobierno de Aragón han considerado que la variación poblacional operada desde los anteriores comicios autonómicos suponga una variación de una entidad suficiente para producir la pérdida de un escaño en la circunscripción menos poblada" o "... la propuesta supone mantener la representación actual, sin modificación alguna, entendiendo que aún no se ha producido un movimiento demográfico de una entidad tal que implique de modo obvio una descompensación de representación de Teruel respecto a Zaragoza y por tanto la necesidad de realizar un cambio tan relevante en la actual composición de la Cámara". El Informe basaba su posición en la amplitud de posibilidades permitida por el tenor del artículo 152.1 CE, así como en un sentido igualmente amplio del término "habitantes" contenido en el artículo 36 EAAr.

Determinantes resultaron también otros dos argumentos. En primer lugar, el apoyo en los Pactos Autonómicos de 1981. De aquellos Pactos proviene la introducción del coeficiente corrector del 2,75 (siendo Aragón la única Comunidad Autónoma, como bien recuerda la Letrada Mayor, que lo mantiene). Y fue en estos primeros Pactos Autonómicos precisamente la población censal la que sirvió para calcular los coeficientes correctores, que iban de una proporción 1-1 a otra 1-2,75. En segundo lugar, se recordaba el Informe que el 24 de febrero de 2009 emitió el Consejo de Estado acerca de las propuestas de modificación del régimen electoral, en el cual puede leerse lo que sigue: “... un respeto escrupuloso al principio de igualdad de voto llevaría a afirmar que el criterio más adecuado para el prorrateo de escaños entre circunscripciones es [el] del número de electores inscritos"15. No obstante, el Consejo de Estado incorporaba algunos inconvenientes ante esta solución, referidos a los menores de edad y a los extranjeros residentes, inconvenientes de los que también se

15 CONSEJO DE ESTADO, Informe del Consejo de Estado sobre las propuestas de modificación del Régimen Electoral General (https://www.consejo-estado.es/pdf/regimenelectoral.pdf), p. 177. 
hacía eco la Letrada Mayor de las Cortes de Aragón; unos motivos sobre los que se volverá en las consideraciones finales.

En todo caso, la conclusión del Informe era la de sostener la constitucionalidad del cambio normativo que se proponía.

Como con detalle relata Olga Herráiz ${ }^{16}$, el 29 de marzo iba a celebrarse el último Pleno de la legislatura y nueve días antes la Mesa y la Junta de Portavoces acordaron de modo unánime que si en el Pleno del día 29 se tomaba en consideración la Proposición de Ley esta fuera tramitada inmediatamente en lectura única, sin presentación de enmiendas ${ }^{17}$. Sin embargo, fueron presentadas dos Proposiciones de Ley alternativas. Una suscrita por el Grupo Parlamentario Popular y la otra por el Grupo Parlamentario Podemos Aragón y las Agrupaciones Parlamentarias de Chunta Aragonesista y de Izquierda Unida.

El Partido Popular en todo momento mantuvo sus reservas acerca de la constitucionalidad de la reforma y solicitó un informe al profesor Bermejo Latre, administrativista de la Universidad de Zaragoza, quien manifestó una posición crítica acerca de la Proposición de Ley que iba a ir al Pleno del 29 de marzo. Esa crítica se basaba en un entendimiento más estricto del término "habitantes", en entender que un refuerzo del elemento del equilibrio territorial no podía producirse en detrimento del más importante de la representatividad y en este otro argumento que considero especialmente relevante: "(I)a solución propuesta reduce la población representada y lo hace en función no solo de la edad de los representados, sino también de su nacionalidad y de la ostentación por su parte de derechos civiles y políticos, con lo que el sistema se aproximaría a una suerte de sufragio censitario, donde el juego democrático se practicaría exclusivamente por, entre y para los electores"18. La Proposición alternativa presentada por el Grupo Popular apostaba por fijar en catorce el número mínimo de escaños asignado a cada circunscripción, aclarando que -una vez aplicada la corrección del 2,75- en ningún caso podría bajarse de

\footnotetext{
${ }^{16}$ Vid. HERRÁIZ SERRANO, O., "Crónica parlamentaria de la IX Legislatura (2015-2019) en las Cortes de Aragón", op. cit., p. 434.

${ }_{17}^{17}$ Vid. Boletín Oficial de las Cortes de Aragón, núm. 332, 2 de abril de 2019, p. 23.695.

18 José Luis BERMEJO ha incluido las consideraciones que expuso en su Informe en el capítulo correspondiente a "Aragón" dentro del Informe Comunidades Autónomas 2019, publicado por el Observatorio de Derecho Público (IDP, Barcelona, 2019, pp. 105-124). Es en las pp. 115 a 117 donde específicamente se refiere al cambio de la norma electoral aragonesa (la cita concreta incluida en el texto principal proviene de la p. 117).
} 
ese mínimo de catorce. Sobre esta Proposición alternativa se pronunció de nuevo la Letrada Mayor del Parlamento aragonés en un Informe emitido el 25 de marzo de 2019 y en el que comenzaba recordando una vez más lo "inhabitual" de entrar en este tipo de análisis previos de constitucionalidad o legalidad. La Letrada Mayor demostraba que un cambio como el que el Grupo Popular proponía contravendría el EAAr, ya que daría como resultado real una proporción de 2,83 entre el número de habitantes necesario para asignar un escaño en la provincia más poblada y el necesario para hacerlo en la menos poblada. También afirmaba muy acertadamente que "no parece posible que mediante la Ley electoral se establezca una distinción entre escaños fijos y variables a efectos de la aplicación del coeficiente corrector, ya que no lo distingue la literalidad del Estatuto...". Asimismo manifestaba que, aunque una interpretación de la Ley electoral se forzase en este sentido, el tenor literal de la propuesta del Grupo Popular no recogía en ese momento la distinción entre esos dos tipos de escaños y que, incluso considerando superados todos esos reparos nada menores, y aplicando el coeficiente del 2,75 únicamente sobre los veinticinco escaños de cuota de reparto, el resultado final daría treinta y dos escaños para Zaragoza, dieciocho para Huesca y diecisiete para Teruel, es decir, un reparto muy diferente, salvo por lo que hace a la provincia de Huesca.

Por su parte, la otra Proposición alternativa también subía el mínimo de diputados por provincia hasta catorce y el total de parlamentarios de las Cortes hasta sesenta y nueve, con la particularidad en este caso de que los tres partidos políticos que estaban tras ella habían sido firmantes de la Proposición de Ley originaria.

Ha de recordarse que ninguna de las dos Proposiciones de Ley alternativas fueron aceptadas y que la originaria fue tomada en consideración por una mayoría de cincuenta y un votos a favor y quince abstenciones y finalmente aprobada por unanimidad -el artículo 37.6 EAAr no exigía tanto, sino la mayoría absoluta-, contando por tanto también con el apoyo de los diputados del Grupo Popular, incierto hasta el último momento ${ }^{19}$. Algo de desconcierto o de cautela se había introducido asimismo tres días antes cuando el Consejo de

\footnotetext{
19 "Un cambio tan importante en un elemento del sistema electoral aragonés no tendría que haber sido adoptado en el tiempo de descuento de la legislatura y de forma tan inesperada, como lo fue, a última hora, el voto afirmativo del Grupo Popular, que evitó la retirada de la iniciativa a que estaba dispuesto el Grupo Socialista si no había consenso", en HERRÁlZ SERRANO, O., "Crónica parlamentaria de la IX Legislatura (2015-2019) en las Cortes de Aragón", op. cit., p. 435.
} 
Gobierno de la Diputación General de Aragón (gobernada entonces, no se olvide, por una coalición PSOE-CHA) aprobó un Acuerdo en relación con la toma en consideración de la Proposición de Ley que nos ocupa con el siguiente tenor: "Se acuerda tomar conocimiento de la Proposición de Ley de modificación de la Ley 2/1987, de 16 de febrero, Electoral de la Comunidad Autónoma de Aragón, presentada por los Grupos Parlamentarios Socialista, Podemos Aragón, Aragonés y Mixto ( $\mathrm{CHA}$ e IU), si bien se entiende que existen alternativas más adecuadas y ajustadas a las previsiones estatutarias para conseguir el fin pretendido"20.

De este modo, el 29 de marzo las Cortes de Aragón aprobaron la Ley 9/2019, de modificación de la Ley 2/1987, de 16 de febrero, Electoral de la Comunidad Autónoma de Aragón, bajo cuya vigencia se celebraron los comicios de mayo de 2019 y que continúa en vigor en el momento de escribir estas líneas a finales de 2020 y comienzos de 2021, sin que haya tenido lugar ninguna otra modificación legislativa o estatutaria en esta materia. La norma cuenta con un artículo único, por el cual se le da una nueva redacción al artículo 13 LEAr consistente en sustituir los términos población de derecho o población sin más por población censal o población incluida en el censo electoral. Muy significativa es la justificación del cambio, incluida en el Preámbulo: "Frente a la pérdida de población del medio rural aragonés, y especialmente en las provincias menos pobladas, como es el caso de Teruel, la aplicación estricta de la Ley ocasionaría que perdiera su diputado número 14, quedándose con 13 escaños, asignándoselo a Zaragoza, que pasaría de 35 a 36 escaños. En un momento en el que la despoblación está en la agenda política, parece poco razonable que las Cortes aragonesas, en desarrollo de su función legislativa, no actúen en la norma de referencia para evitar que se produzca esta situación de pérdida de representación en la provincia de Teruel".

Una vez expuesto el recorrido de por qué y cómo se ha llegado a la actual regulación, se hace necesario concluir con una serie de valoraciones.

El primer aspecto que merece un comentario crítico ha sido ya apuntado y es el de la imprevisión. "Nunca mejor dicho, las prisas no son buenas consejeras", escribe con razón Olga Herráiz ${ }^{21}$; pero es que además en este caso podría

${ }^{20}$ Boletín Oficial de las Cortes de Aragón, núm. 332, 2 de abril de 2019, p. 23.695 (la cursiva es mía).

${ }^{21}$ HERRÁIZ SERRANO, O., "Crónica parlamentaria de la IX Legislatura (2015-2019) en las Cortes de Aragón", op. cit., p. 435. 
perfectamente haberse prescindido de esas prisas si existía la voluntad de mantener el escaño número catorce para la provincia de Teruel, ya que, como sabemos, era un objetivo en torno al cual bien podría haberse comenzado a trabajar desde el inicio de la legislatura ${ }^{22}$.

La segunda consideración lo es más de fondo y está relacionada con la corrección o no de la solución adoptada desde un punto de vista jurídico-constitucional. En esta línea, defiendo una posición cercana a la que sostenía el profesor Bermejo Latre en su Informe. Me parece adecuado el recordar algunos de los elementos centrales de la teoría de la representación, especialmente aquellos que protagonizaron el tránsito del sufragio entendido como función al sufragio entendido como derecho. En los albores de la representación política, "(I)a titular de la representación era la nación y la nación era también, por consiguiente, la que otorgaba el título de elector a los ciudadanos que creyera conveniente: de ahí, la presencia de los requisitos que se exigían. El estatus de elector se convertía, de esa manera, en una función; una función concedida por la sociedad -entiéndase por la nación-y que quien la ejercía lo hacía por todos los ciudadanos" ${ }^{23}$. Pero ese escenario inicial se vería sustituido, gracias al avance y la consolidación histórica de la democracia, por otro en el que "(I)a elección será entonces un derecho que, como tal, se ejercerá de manera individual. El pensamiento y la práctica democráticos dan lugar al nacimiento de la elección tal y como hoy la entendemos: un derecho político que los ciudadanos ejercen individualmente, precisamente por su condición de ciudadanos, requisito esencial para su ejercicio"24.

Siendo esto así, la reforma operada por la Ley aragonesa 9/2019 pareciera una vuelta a situaciones históricas muy superadas, en la medida en que la representación se entiende como un mecanismo para cumplir una función y no tanto para articular el ejercicio de unos derechos políticos. Es cierto que la población extranjera carece de derecho de sufragio en las elecciones autonómicas, pero una reforma de este tipo supone un claro posicionamiento (en mi opinión, en un sentido de paso atrás democrático) en los cada vez más

\footnotetext{
22 "Cabe afirmar, a la vista de la atropellada tramitación de la norma y de la solución finalmente adoptada (...) que el objetivo se ha cumplido de una forma ciertamente discutible y que habría merecido una solución más meditada (cabe recordar que en las elecciones autonómicas precedentes ya el decimocuarto escaño por Teruel había dependido de solo pocos cientos de habitantes)", en BERMEJO LATRE, J. L., "Aragón", op. cit., p. 115.

23 CEBRIÁN ZAZURCA, E., Sobre la democracia representativa. Un análisis de sus capacidades e insuficiencias, Prensas de la Universidad de Zaragoza, Zaragoza, 2013, p. 62. ${ }^{24}$ Ibid., pp. 62-63.
} 
persistentes debates acerca de si no sería más correcto que el voto se ejerciese por parte de quienes habitan el lugar en el que radican las instituciones cuya representación o gestión se dilucida en el proceso electoral. Pero, sin necesidad de profundizar en cuestiones que nos apartarían del tema, lo que sí parecía asumido y fuera de duda era que ese sector de la población sí era tenido en cuenta para determinar el número de escaños correspondiente a cada circunscripción. El sustraerlos de esa cifra los convierte definitivamente en invisibles políticamente.

Con todo, estimo que el problema principal reside en un aspecto concreto que parece haberse pasado por alto por parte de todos o casi todos los actores implicados de un modo u otro en este proceso de reforma legislativa. Me refiero a la situación de los menores de edad. Si con respecto al estado de los extranjeros pueden existir más cuestiones debatibles o sujetas a interpretación, cuando hablamos de los menores las dudas se disipan. Una persona menor de edad es titular de un modo pleno de todos los derechos fundamentales. Tan solo es en la esfera del ejercicio de algunos de ellos -y siempre, en todo caso, de un modo excepcional y atendido el propio interés del menor- donde pueden establecerse limitaciones, que por su propia esencia son temporales. Por lo tanto, como ha recordado Benito Aláez, "(I)a minoría de edad no es un status jurídico que prohíba el acceso al ejercicio de los derechos fundamentales" 25 . Siguiendo con las reflexiones del profesor Aláez, no ha de olvidarse que "el derecho de sufragio garantizado en el artículo 23.1 CE -que, por otra parte, a diferencia de otros textos constitucionales europeos, no ha establecido una edad mínima para su ejercicio- no se agota en su principal facultad de voto, sino que también incluye otras facultades..."26. En efecto, entre esas otras facultades -en línea con la teoría de la representación que antes sacaba a colación- se encuentra el derecho a ser representado. La propia dicción del artículo 23 de la Constitución, al referirse al derecho a participar en los asuntos públicos por medio de representantes, ha de interpretarse en el sentido de que los menores de edad -aunque todavía no puedan votar- cuentan con unos representantes a través de los cuales ese grupo poblacional también está participando en los asuntos públicos. No contar con todas aquellas personas

\footnotetext{
${ }^{25}$ ALÁEZ CORRAL, B., "Los sujetos de los derechos fundamentales", en BASTIDA FREIJEDO, F. J., VILLAVERDE MENÉNDEZ, I., REQUEJO RODRÍGUEZ, P., PRESNO LINERA, M. Á., ALÁEZ CORRAL, B. y FERNÁNDEZ SARASOLA, I., Teoría general de los derechos fundamentales en la Constitución española de 1978, Tecnos, Madrid, 2012, p. 95.

${ }^{26}$ Ibid., pp. 86-87.
} 
que todavía no han cumplido la edad de voto supone conculcar su derecho a la participación política y no otra cosa es lo que se ha hecho con la desafortunada reforma electoral aragonesa ${ }^{27}$.

Los menores están viendo negado su derecho fundamental de participación en los asuntos públicos por mor de una norma que, aunque no lo pretendiera como objetivo, es la consecuencia que sin embargo ha provocado; una norma, por lo tanto, y en mi opinión, inconstitucional.

A mayor abundamiento, el término "habitantes" utilizado en el artículo 36 EAAr es sinónimo de "población" (tal y como se entendía en la antigua redacción del artículo 13 LEAr), y no de "población censal". Por lo que la inconstitucionalidad del precepto vendría también dada por su concreta naturaleza antiestatutaria.

Para terminar, una última consideración es necesaria. $Y$ no es otra que la que apunta al núcleo de la cuestión que en realidad estamos debatiendo en estas páginas, una cuestión que además se conecta con el valor y la importancia que deseemos conceder a nuestro Estado de Derecho y a nuestras instituciones de autogobierno. Sin duda, el Derecho es la herramienta para dar solución a las demandas de una sociedad, pero como trasfondo de todo lo narrado en este capítulo creo identificar un exceso de entendimiento del Derecho como varita mágica de la que disponer a placer más que para modificar la realidad, para maquillarla, tratando, en un gesto gatopardesco, de salvar el expediente. El respeto al ordenamiento jurídico exigiría asumir las consecuencias de la aplicación de la regla matemática contenida en la LEAr hasta su última reforma. Las matemáticas poseen una exactitud que concede poco margen de interpretación, por ello argumentos basados en que el límite ha sido solo superado por muy poco no son serios ni defendibles desde ningún punto de vista. Esta actitud alcanza su máximo nivel cuando el Preámbulo de la Ley 9/2019 -en la parte transcrita antes- habla de la consecuencia que ocasionaría "la aplicación estricta de la Ley", como si las normas pudieran aplicarse según una escala gradual. Si disponíamos de esa regulación es porque considerábamos que se ajustaba a la interpretación que de la realidad

${ }^{27}$ Distinta es la opinión de la Comisión de Venecia cuando contempla en el Código de buenas prácticas en materia electoral como criterios posibles para el reparto de los escaños el de los residentes en la circunscripción, los nacionales residentes (incluyendo menores), los electores inscritos o los votantes reales, vid. EUROPEAN COMMISSION FOR DEMOCRACY THROUGH LAW, Code of Good Practices in Electoral Matters. Guidelines and Explanatory Report, CDL-AD (2002), I. 2.2 (https://www.venice.coe.int/webforms/documents/default.aspx?pdffile=CDL$\mathrm{AD}(2002)$ 023rev2-cor-e). 
efectuábamos, entendiendo que si esa realidad cambiaba los efectos que ese cambio produjese serían los establecidos en esa propia regulación. Cambiar las reglas del juego cuando cambia la situación (no por ninguna causa sobrevenida, lo cual sería muy adecuado; sino únicamente por la materialización de una circunstancia que se contemplaba en la propia ley) supone hacer de menos al Derecho y concederle un valor mucho más escaso del que merecería.

Que la circunscripción de Teruel perdiera un escaño en las Cortes de Aragón era la consecuencia de una pérdida demográfica. Con la medida adoptada no se ha solucionado ningún problema demográfico y, además, se ha creado otro importante problema en el ámbito de la constitucionalidad, de la representatividad democrática y del respeto a los derechos fundamentales de toda la población. No quiero con esto decir que no podamos replantearnos con mayor sosiego y con mejor técnica jurídica el ampliar el número de escaños de una provincia como la turolense -argumentos para ello no faltan-, aunque sí creo que debería hacerse, en tal caso, sin olvidar que se requeriría una previa reforma del Estatuto de Autonomía y sin olvidar tampoco que lo que el artículo 152.1 CE prioriza es la representación proporcional ${ }^{28}$. En este sentido, José Ramón Montero y Pablo Oñate pusieron ya hace años de manifiesto cómo la norma electoral aragonesa diseñaba unos distritos de gran magnitud, lo cual favorecía la proporcionalidad de los mismos, si bien el reparto entre ellos era desigual, dando lugar al final a una descompensación al tomar los resultados globales del conjunto de la Comunidad Autónoma ${ }^{29}$. Esta consecuencia, habitual por otra parte y "buscada" con el fin de lograr también otros objetivos, queda algo más reforzada -y la proporcionalidad, por tanto, algo más deteriorada- tras la última reforma. A la espera, en su caso, de los cambios que puedan tener lugar en un futuro -la tendencia de la evolución poblacional en Teruel sigue a la baja...-, lo que por el momento tenemos es una artimaña

\footnotetext{
${ }^{28}$ El Consejo de Gobierno celebrado por el Gobierno de Aragón el día 10 de marzo de 2021 ha aprobado la toma en conocimiento del Anteproyecto de Ley para la Reforma del Estatuto de Autonomía de Aragón, en el que se propone "la modificación del artículo 36 del vigente Estatuto de Autonomía con el fin de asegurar el mantenimiento de la representatividad de las provincias menos pobladas, consolidando un modelo territorial equilibrado que combine adecuadamente los criterios territoriales y poblacionales", con el fin de mantener los catorce diputados mínimos por provincia en las elecciones a las Cortes de Aragón (http://www.aragonhoy.net/index.php/mod.noticias/mem.detalle/id.273616).

${ }^{29}$ MONTERO, J. R. y OÑATE, P., "El sistema electoral", en CHUECA, R. y MONTERO, J. R. (eds.), Elecciones autonómicas en Aragón, Tecnos - Gobierno de Aragón, Madrid, 1995, pp. 65-84 (passim).
} 
que, como en otro lugar escribí, "tan solo se limita a esconder el polvo debajo de la alfombra, ${ }^{, 30}$. Una estrategia fallida, puesto que el objetivo no debiera ser el de corregir, ocultándolos, los efectos de la despoblación, sino el de articular soluciones que tratasen de corregir, mitigándola, la propia despoblación. Esta sería la mejor manera de conservar el escaño catorce de Teruel.

Joaquín Carbonell, turolense de Alloza a cuya memoria dedico estas líneas, cantaba en De Teruel no es cualquiera: "Una vez me pasé en soledad / siete días sin hablar". Pónganse en marcha políticas que contribuyan a llenar de voces reales ese territorio en lugar de llenarlo de altavoces con grabaciones que crean una ilusión. Esto último -como se señala en el título- no es sino hacerse trampas al solitario.

${ }^{30}$ CEBRIÁN ZAZURCA, E., "Crónica de las elecciones a las Cortes de Aragón de 26 de mayo de 2019", op. cit., p. 89. 